\section{ON THE IDENTIFICATION AND MISIDENTIFICATION OF BUTTERFLIES OF THE GARO HILLS}

\author{
Krushnamegh Kunte ${ }^{1,2}$, Gaurav Agavekar ${ }^{1,2}$, Sanjay \\ Sondhi ${ }^{2,3}$, Rohan Lovalekar ${ }^{2} \&$ Kedar Tokekar ${ }^{2}$
}

${ }^{1}$ National Center for Biological Sciences, GKVK, Bellary Road, Bengaluru, Karnataka 560065, India, ${ }^{2}$ Indian Foundation for Butterflies, Bengaluru, ${ }^{3}$ Titli Trust, Dehradun, Uttarakhand, India

krushnamegh@ncbs.res.in, krushnamegh@ifoundbutterflies.org (corresponding author),

Monsoon Jyoti Gogoi reviewed our book on the butterflies of the Garo Hills (Sondhi et al. 2013) in the 26 June issue of Journal of Threatened Taxa (Gogoi 2013). We recognize the generally positive tone of the review, and also Gogoi's appreciation of our use of the current and updated scientific names of Indian butterflies. We also appreciate the fact that Gogoi highlighted the importance of our book in documenting and conserving butterflies of the Garo Hills, and the user-friendly interface that we have used. However, Gogoi suggested that we have misidentified some of the butterfly images in our book, attributing them to wrong species. Since more than $50 \%$ of the review was devoted to this with detailed discussion of various species (mis)identifications, it is necessary to set the record straight by demonstrating that our identifications were correct in every case mentioned by Gogoi. We will deal with the identifications and names below as well as in Image 1 in the order in which Gogoi (2013) mentioned the species. For each species pair, our correctly identified species are illustrated on the left and Gogoi's misidentifications are illustrated on the right in Image 1. Our original field images may be compared either from the book, on the Butterflies of India website (http://www.ifoundbutterflies.org/history-of-speciespages-on-butterflies-of-india-website), or in Image 2.

Male Tarucus venosus has a characteristic pale violet-blue forewing upperside with black discal spots and a broad black margin that is broadest at the tornus and tapers off at the apex (Evans 1932, 1955; Cantlie 1962; Image 1). These characters are clearly visible in our field images. Tarucus indica female is largely brown with blue scales at the forewing upperside base, and with white and dark brown spots on the discal and

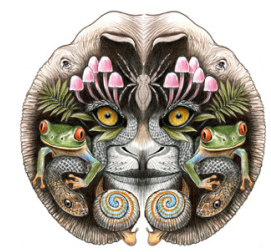

ISSN

Online 0974-7907 Print 0974-7893

\section{OPEN ACCESS} submarginal areas on both wings (Image 1). In male $T$. indica, forewing upperside is transparent pale blue, dark spot at cell-end is usually inconspicuous, and hindwing underside discal spot in 5 is widely separated from the post-discal band (Evans 1955; Cantlie 1962). Tarucus venosus is not uncommon in NE India whereas $T$. indica is known only from Afghanistan to western and southern India, not from northeastern India (Evans 1955). Thus, most of Gogoi's records of "T. theophrastus indica" from NE India should be that of $T$. venosus, not $T$. indica. Indeed, Gogoi's images from Assam (available on the Flutters website, URL given in Gogoi 2013) closely match the characteristic phenotype of venosus, except that his image marked 'male' is actually a female and the image marked 'female' is a male. Moreover, the name combination used by Gogoi, Tarucus theophrastus indica, is 80 years old (Evans 1932) and has been outdated for 58 years since Evans (1955) showed indica to be a distinct species, an arrangement that is widely followed since Cantlie (1962).

Gogoi has correctly identified his Jamides pura, but our identification of $J$. pura was also correct. Our wild-caught specimens of $J$. pura (Image 2), which were photographed and released on the spot with permission from the forest officials, had the characteristic threadlike black border to forewing upperside, which contrasts with the black border that increases in breadth towards the apex in J. celeno (Evans 1932; Image 1). Clearly, Gogoi's observations on the seasonal variation in these two species are limited: in our experience, variation in the wet and dry season forms of both J. celeno and J.

DOI: http://dx.doi.org/10.11609/JoTT.o2710.4616-20 | ZooBank: urn:Isid:zoobank.org:pub:553F36B2-A380-4DFE-A913-57CD8470729E

Date of publication: 26 July 2013 (online \& print)

Manuscript details: Ms \# 02710 | Received 16 July 2013

Citation: Kunte, K., G. Agavekar, S. Sondhi, R. Lovalekar \& K. Tokekar (2013). On the identification and misidentification of butterflies of the Garo Hills. Journal of Threatened Taxa 5(11): 4616-4620; http://dx.doi.org/10.11609/JoTT.03710.4616-20

Copyright: (c) Kunte et al. 2013. Creative Commons Attribution 3.0 Unported License. JoTT allows unrestricted use of this article in any medium, reproduction and distribution by providing adequate credit to the authors and the source of publication. 

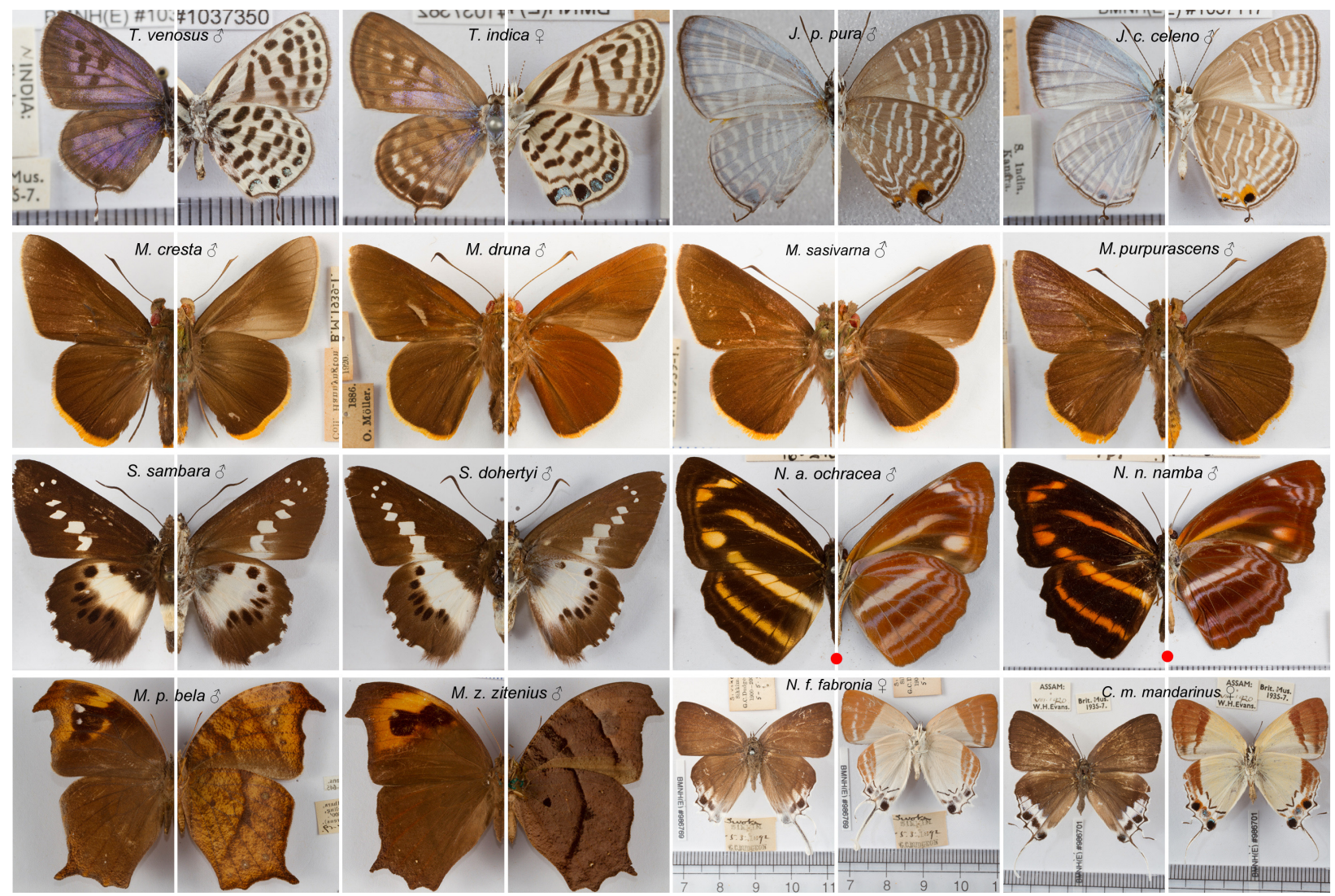

Image 1. Comparison between the correctly identified and misidentified butterfly species mentioned by Gogoi (2013) (except Neocheritra f. fabronia and Charana $m$. mandarinus, see the main text). For each species, the left half shows the upper side and the right half shows the underside of the same specimen. The red dots below Neptis ananta ochracea and $N$. $n$. namba indicate that the images are of the type specimens. Images: Gaurav Agavekar and Krushnamegh Kunte. Copyright: Natural History Museum, London.

pura is broadly overlapping, although frequency of the dry season forms is apparently different in the two species. In addition, not only do these two species occur in the same regions, they also share the same microhabitat in forested areas. The record of J. pura in the Garo Hills is further substantiated by our subsequent records of the wet season form in March and April (Image 2). Separating the two species in either seasonal form from the underside alone, which Gogoi attempted, is not possible.

Regarding Heliophorus, Evans (1932) and Cantlie (1962) had treated indicus as a valid subspecies of epicles, and latilimbata as a synonym of indicus. Gogoi (2013) relied on this 50- to 80-year old and equally outdated arrangement in his review. However, Eliot (1963) had shown, based on differences in the structures of male genitalia, that epicles and indicus are distinct species and he had treated latilimbata as a subspecies of epicles. Subsequent authors, including us, have widely followed Eliot's proposal of listing indicus and epicles as separate species, and treating latilimbata as a subspecies under epicles (further references at http://yutaka. it-n.jp/lyc4/81520010.html and http://yutaka.it-n.jp/ lyc4/81530001.html). We note that Gogoi had also cited the Global Lepidoptera Names Index (LepIndex), created by the Natural History Museum, London (NHM), as a taxonomic source for treating latilimbata as a synonym of $H$. indicus. Leplndex is a record of the taxon index cards used at the museum, which are very important and useful historical documents. However, these index cards have not been updated for butterfly names in decades and therefore they have not incorporated important taxonomic information and arrangements generated by many of the museum's own butterfly taxonomists and prominent visitors. Butterfly naturalists should use the names and taxonomic arrangements given on Leplndex only after double-checking them with modern taxonomic references and resources. One of us (KK) is in talks with the Lepidoptera curators at the NHM to update the taxonomy of Indian butterflies as reflected in Leplndex and the organization of species, subspecies and specimens at the museum. 


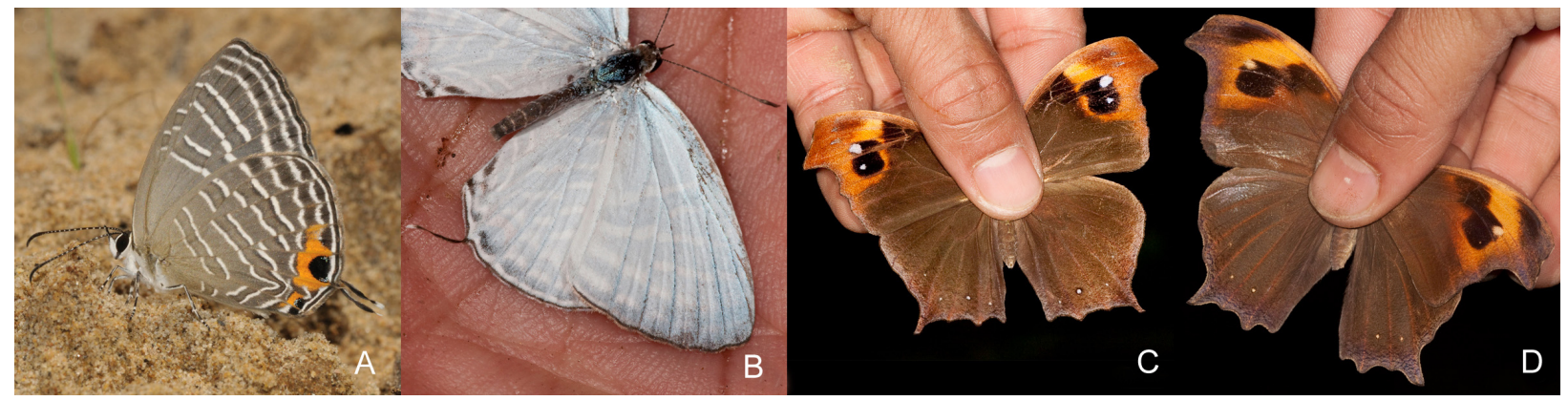

Image 2. Images of wild and wild-caught butterflies to illustrate key distinguishing features of Jamides pura, Melanitis phedima and M. zitenius specimens photographed in the Garo Hills and used in both our paper and the book. Image copyright: A: Sanjay Sondhi, B-D: Krushnamegh Kunte.

KK has photographed the entire Indian portion of Evans's Hesperiidae Reference Collection that is maintained to this day at the NHM. This was the very collection on which Evans (1949) had based his keys to Hesperiidae. KK has also photographed all the Indian species and subspecies of Hesperiidae at the NHM, which was organized at the museum by Evans himself after consolidating various private and mixed collections housed at the NHM in Evans's day. Based on a close look at these two collections at the NHM and the large collection of reference photographs that KK has taken in these collections, we know that the identification key to Matapa given in Evans (1949) is not very clear. It is sometimes difficult to identify species based solely on this key. After comparing our field images with the specimens at the NHM as well as a careful reading of Evans's key, we are confident of our identifications of $M$. cresta and M. sasivarna. Briefly, M. cresta has prominently much paler forewing underside apex and hindwing underside base compared to $M$. druna (Evans 1949; Image 1). This character is clearly seen in KK's image that was used in Kunte et al. (2012) as well as Sondhi et al. (2013).

The characters to distinguish between Matapa sasivarna and M. purpurascens, mentioned by Gogoi from Evans (1949), are indeed correct. However, his reading of these characters on KT's image is incorrect. As mentioned in Evans's (1949) key, our specimen of $M$. sasivarna had very dark underside with darker veins, end of abdomen orange, and bluish-green metallic sheen on the thorax and bases of wings. Image 1 illustrates key differences between the above four Matapa species. Our Matapa specimens match the keys as well as the museum specimens (Kunte et al. 2012; Sondhi et al. 2013).

Similarly, the difference in the relative distances of black spots in spaces 6 and 7 on the hindwing underside, which distinguishes Seseria sambara fromS. dohertyi, was correctly mentioned by Gogoi from Evans (1949) [except that Gogoi erroneously mentioned spots in spaces 7, 6 and 5; see Evans (1949, pp. 123-124)]. However, Gogoi's reading of this character in our images was incorrect: the outer spot in 7 is approximately mid-way between the spot in 6 and the inner spot in 7, as expected for S. sambara but not $S$. dohertyi (compare with Image 1 ). Additionally, S. sambara has a narrower white band on hindwing compared to that in S. dohertyi (Evans 1949), as seen in our images from the Garo Hills. Incidentally, the two Seseria specimens used in Gogoi's identification key on the Flutters website, referenced by Gogoi (2013), are both S. sambara, and not S. sambara and S. dohertyi as claimed by Gogoi. The correctly identified images of S. sambara and S. dohertyi showing their distinguishing characters can be seen on the Butterflies of India website (http://www.ifoundbutterflies.org/358-seseria/seseriasambara\#!/sp/1151/Seseria-sambara and http://www. ifoundbutterflies.org/358-seseria/seseria-sambara\#!/ $\mathrm{sp} / 1150 /$ Seseria-dohertyi).

Our Neptis from the Garo Hills may very well be $N$. namba and not N. ananta, as Gogoi suggested. We carefully compared both the species at the time of confirming identifications for the book but could not reach a firm conclusion about this image. This is because many of the important distinguishing features are not clear in SS's photograph, which was the only image taken at the time. So we have tentatively listed the butterfly as $N$. ananta but we await further sightings and better images or specimens before we revisit the identification. We point out that distinguishing between $N$. ananta and N. namba is more complex than suggested by Gogoi. Eliot (1969) has provided a detailed treatment of this species group, which we have followed for the identification and names of Indian Neptis.

The identification of the three Indian species of 
Melanitis is relatively easy when one has seen the uppersides as well as the undersides of specimens and when one knows the full range of variation seen in the three species. However, the identification details of this species group are very complex and beyond the scope of this rebuttal, they will instead be provided in KK's upcoming books on Indian butterflies (see below). We will only state here that we are intimately familiar with all the known variation in these species from the hundreds of specimens that we have seen in nature (see some examples on the Butterflies of India website, http://www.ifoundbutterflies.org/427-Melanitis-dp3), dozens of specimens of each species that we have raised from early stages (URL as above), and dozens more specimens that we have photographed at the NHM. Therefore we are reasonably certain of our identification of these three species. As proof, we provide the upper sides (Image 2) of the specimens of $M$. phedima and M. zitenius used in our book, and photographed in the Garo Hills, to compare them with the matching reference images from the NHM (Image 1). Dozens of our images of $M$. leda from the Garo Hils and nearby regions are available on the Butterflies of India website (http://www.ifoundbutterflies.org/427-Melanitis-dp3-!/ sp/503/Melanitis-leda).

Lastly, Gogoi doubted our records of two species from the Garo Hills as unlikely for this region of northeastern India: Pareronia hippia (misspelled 'hippai' by Gogoi) and Hypolimnas misippus (misspelled 'Hypolimnias' by Gogoi). Of these, our record of P. hippia is indeed unconfirmed ("our sighting needs confirmation since this specimen could not be photographed", Kunte et al. 2012). However, P. hippia does occur near the Garo Hills and therefore not unlikely in our study area: Larsen (2004) has mentioned several records from the neighboring areas in Bangladesh; specifically from Dhaka, Sylhet, Teliapara, and Rangamatti (Chittagong Hill Tracts). On the other hand, $H$. misippus very much occurs not only in northeastern India but also all the way to Indo-China (EkAmnuay 2007; Inayoshi 2013; Pinratana \& Eliot 1996). Our record of this distinctive species was based on four specimens that we have seen very well in the Garo Hills (Kunte et al. 2012), leaving no room for misidentification. We have recorded this species in several other states of NE India as well.

We take this opportunity to point out two errors in identification in our paper (Kunte et al. 2012), which we were able to correct in our book after KK and GA's work at the NHM from September to November 2012. In the paper we had erroneously used an image of Hyarotis microstictum Wood-Mason \& de Nicéville, 1887 (Small
Brush Flitter) in place of Zographetus ogygia ogygia Hewitson, 1866 (Continental Purple-spotted Flitter). The correctly identified images of both the species are now available on the Butterflies of India website (http://www.ifoundbutterflies.org/history-of-speciespages-on-butterflies-of-india-website). Similarly, we had erroneously used an image of the female Charana mandarinus mandarinus Hewitson, 1863 (Sylhet Mandarin Blue) in place of Neocheritra fabronia fabronia Hewitson, 1878 (Indo-Chinese Pale Grand Imperial). KK had initially identified RL's image of $C$. mandarinus as that of $N$. fabronia based on the specimen illustrated elsewhere (Corbet et al. 1992), which was the only reference image available to us in 2010 and 2011 when KK had done the species determination. RL was able to take only the upperside image of his specimen, from which separation between the two species was previously difficult. After his work at the NHM in late 2012, KK revisited this identification and this time determined RL's image to be that of $C$. mandarinus based on the very subtle differences, clear in our reference images, on the upper side that separate these two species. These differences have never been satisfactorily illustrated before, and only inadequately described in literature. Therefore, we provide the images of uppersides of these species (Image 1) for the benefit of the larger butterflywatching community. The undersides of these species are, of course, distinct and have been clearly illustrated elsewhere (Kunte et al. 2013). Both the species ( $Z$. ogygia and $C$. mandarinus) have been represented in our book with correctly identified images.

We would like to end by pointing out that our recent identifications of Indian butterflies are based on not only all the historical literature and taxonomic keys, which we have extensively referenced for our various works in the past few years, but also on approximately 25,000 reference images of museum specimens from the NHM and the Museum of Comparative Zoology (Harvard University, Cambridge). These materials are currently being prepared for print publication in the form of two comprehensive books and online publication on the Butterfliesof Indiawebsite(http://www.ifoundbutterflies. org/) so that they are widely accessible to all. On the other hand, most of the image identifications and scientific name combinations used on currently available non-peer-reviewed web-resources such as Flickr and the Flutters website, referenced by Gogoi, are based on 60 to 100 years old literature (examples cited by Gogoi 2013). Large sections of this old literature are either taxonomically outdated or scientifically inadequate in light of the academic developments in the past decades. 
So we agree with Gogoi that caution is indeed required in the identification of Indian butterflies from difficult species groups. However, we have demonstrated our extreme caution and meticulous attention to detail in species identification and taxonomic validity with our track record on these matters in our recent publications and the Butterflies of India website. We hope that Gogoi and other young, promising Indian butterfly naturalists and biologists will follow suit in their identifications, writings and scientific publications with careful work in the future.

As of now, we know of no misidentifications in our book, with the potential exception of the Neptis ananta- $N$. namba species pair (see above). If any misidentifications are discovered in the future, they will be listed, along with correct identifications and reference images, on the webpages of this book on the Butterflies of India (http:// www.ifoundbutterflies.org/bibliography/publicationsbutterflies-of-the-garo-hills) and the Titli Trust (http:// www.titlitrust.com/Garo_Hills_Book.html) websites. As always, we welcome well-articulated constructive criticism and comments from all, and we will be happy to learn from others.

\section{REFERENCES}

Cantlie, K. (1962). The Lycaenidae Portion (Except the Arhopala Group), of Brigadier Evans' The Identification of Indian Butterflies 1932 (India, Pakistan, Ceylon, Burma). Bombay Natural History Society, Mumbai, 159pp.
Corbet, A.S., H.M. Pendlebury \& J.N. Eliot (1992). The Butterflies of the Malay Peninsula. $4^{\text {th }}$ revised edition. Malayan Nature Society, Kuala Lumpur, 595pp.

Ek-Amnuay, P. (2007). Butterflies of Thailand. Baan Lae Suan-Amarin Printing and Publishing Co., Bangkok, 865pp.

Eliot, J.N. (1963). The Heliophorus epicles (Godart, 1823) (Lepidoptera: Lycaenidae) complex. Entomologist 96: 169-180.

Eliot, J.N. (1969). An analysis of the Eurasian and Australian Neptini (Lepidoptera: Nymphalidae). Bulletin of the British Museum of Natural History (Entomology) Supplement 15: 3-155.

Evans, W.H. (1932). The Identification of Indian Butterflies $-2^{\text {nd }}$ edition. Bombay Natural History Society, Mumbai, 454pp.

Evans, W.H. (1949). A Catalogue of the Hesperiidae from Europe, Asia and Australia in the British Museum (Natural History). British Museum (Natural History), London, 502pp.

Evans, W.H. (1955). A revision of the genus Tarucus (Lepidoptera: Lycaenidae) of Europe, North Africa and Asia. Entomologist 88: 179-187.

Gogoi, M.J. (2013). Book Review: Butterflies of the Garo Hills. Journal of Threatened Taxa 5(10): 4527-4528.

Inayoshi, Y. (2013). A Check List of Butterflies in Indo-China (chiefly from Thailand, Laos and Vietnam). http://yutaka.it-n.jp/, accessed July 2013.

Kunte, K., S. Kalesh \& U. Kodandaramaiah (eds.). (2013). Butterflies of India, v.2.00. Indian Foundation for Butterflies, Bengaluru. http:// www.ifoundbutterflies.org, accessed July 2013.

Kunte, K., S. Sondhi, B.M. Sangma, R. Lovalekar, K. Tokekar \& G. Agavekar (2012). Butterflies of the Garo Hills of Meghalaya, NE India: their diversity and conservation. Journal of Threatened Taxa 4(10): 2933-2992; http://dx.doi.org/10.11609/JoTT.o2945.2933-92

Larsen, T.B. (2004). Butterflies of Bangladesh-An Annotated Checklist. IUCN Bangladesh Country Office, Dhaka, 147pp.

Pinratana, A. \& J.N. Eliot (1996). Butterflies in Thailand. Vol. 3: Nymphalidae ( $2^{\text {nd }}$ revised edition.). Brothers of St. Gabriel in Thailand, Bangkok, 140pp.

Sondhi, S., K. Kunte, G. Agavekar, R. Lovalekar \& K. Tokekar (2013). Butterflies of the Garo Hills. Samrakshan Trust (New Delhi), Titli Trust (Dehradun) and Indian Foundation for Butterflies (Bengaluru), 200pp. 